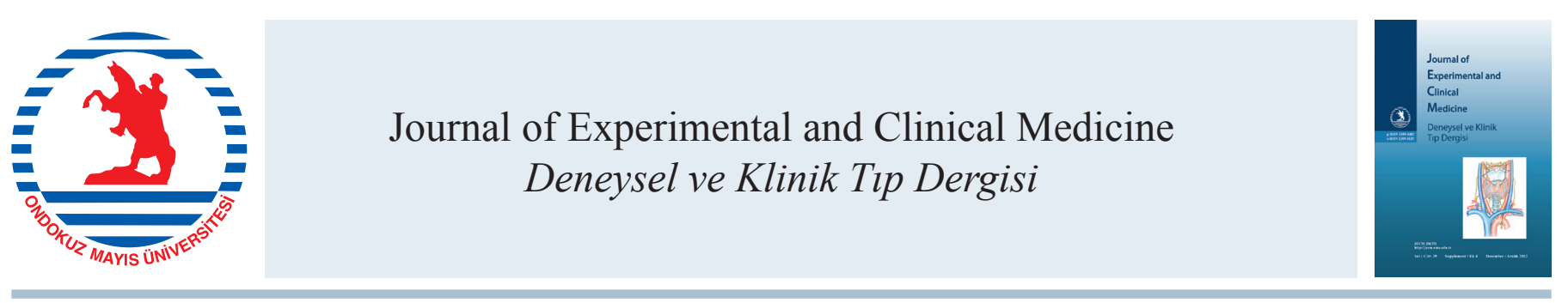

Derleme / Review

doi: $10.5835 /$ jecm.omu.29.s4.014

\title{
İyot metabolizması
}

Iodine metabolism

Ali Okuyucu, Hasan Alaçam*

Ondokuz Mayıs Üniversitesi, Tıbbi Biyokimya Anabilim Dalı, Tıp Fakültesi, Samsun, Türkiye

\begin{tabular}{|c|c|}
\hline MAKALE I & GÍLERİ \\
\hline Makale geçı & \\
\hline Geliş tarihi & : 07 / 06 / 2012 \\
\hline Kabul tarihi & : $03 / 12 / 2012$ \\
\hline
\end{tabular}

\section{* Yazışma Adresi:}

Hasan Alaçam

Ondokuz Mayıs Üniversitesi,

Tıp Fakültesi,

T1bbi Biyokimya Anabilim Dalı

Samsun

e-posta: hasanalacam@hotmail.com

\section{Anahtar Kelimeler:}

Iyot

T3

T4

Tiroit peroksidaz

TSH

\section{Keywords:}

Iodine

T3

T4

Thyroperoxidase

TSH

\section{ÖZET}

Vücudumuzda bulunan iyotun major kaynağı diyettir. Diyetle alınan iyot moleküler $\left(I_{2}\right)$ formda ise kolaylaştırılmış difüzyonla emilirken, iyodür formunda ise (I-) emilimi gastrik mukozada bulunan sodyum-iyodür simporter taşıyıcı proteini yardımı ile gerçekleşir. İnsanlarda, tubuler sekresyonu veya aktif transportuna dair bilgi olmadığından, renal klirensi öncelikle glomerüler filtrasyona bağlıdır. İnorganik iyot, folikül hücrelerinin kapillere yakın bazolateral membranında yerleşmiş olan ve elektrokimyasal gradyente karşı iki $\mathrm{Na}^{+}$iyonu ve bir I- iyonunun hücre içine geçişini sağlayan sodyum-iyodür simporter'i ile hücre içine alınır. Bu pompanın aktivitesi tiroit stimülan hormon (TSH) ile arttırılır ve bu pompa tiroit hormonlarının sentezinde hız sınırlayıcı basamaktır. İyodürün folikül lümenine geçmesi için gerekli ikinci transport sistemi; tiroit hücresi apikal membranını geçerek kolloide girmesini sağlayan pasif transporttur. Tiroit hormon sentezinin ilk adımı tiroglobulindeki tirozil kalıntılarına iyodürün eklenmesidir. Bu eklenme apikal plazma membranı-folikül lümeni sınırında, $\mathrm{H}_{2} \mathrm{O}_{2}$, thyroperoxidase (TPO), iyodür ve tiroglobulin varlığında oluşur. İlk olarak iyodür okside olur ve daha sonra tiroglobulinin tirozil kalıntısı ile birleşir. Hormon sentezinde sonraki adım komşu iki monoiyodotirozil (MIT) kalıntısının diiyodotironin (DIT) oluşturmak üzere birleşmesidir. İki DIT birleşerek tiroksini (T4), bir DIT ve bir MIT birleşerek triiyodotironini (T3) oluşturur. Bu reaksiyonu TPO katalizler.

J. Exp. Clin. Med., 2012; 29:S277-S279

\section{ABSTRACT}

The major source of iodine contained in our body comes from our diet. If the iodine taken via diet is in the molecular form $\left(\mathrm{I}_{2}\right)$, it is absorbed by facilitated diffusion, if in the iodide form, then the $\left(\mathrm{I}^{-}\right)$absorption takes place with the help of sodium-iodide symporter carrier protein present in the gastric mucosa. Since, in humans, no information exists on tubular secretion or active transport, renal clearance first of all depends on the glomerular filtration. Inorganic iodine is ingested into the cell through iodide symporter which is located in the basolateral membrane, close to the capillary, of follicle cells and enables cell ingestion of two $\mathrm{Na}^{+}$iodine and one $\mathrm{I}^{-}$iodine against electrochemical gradient. The activity of this pump is enhanced by TSH and this pump is the rate-limiting step in the synthesis of thyroid hormones. The second transport system required for transporting the iodide into the follicle lumen is the passive transport which enables it to enter into colloid after passing through thyroid cell apical membrane. The first step of the thyroid hormone synthesis is the addition of iodide to the tyrosyl residues in the thyroglobuline. This addition takes place at the boundary of apical plasma membrane and follicle lumen and in existence of $\mathrm{H}_{2} \mathrm{O}_{2}$, thyroperoxidase (TPO), iodide and thyroglobuline. First iodide becomes oxidised and then combines with tyrosyl residues of thyroglobuline. The next step in the hormone synthesis is the amalgamation of two neighbouring monoiododetyrosyl (MIT) residues to generate diiodothyronine (DIT). Two DITs amalgamate to generate T4, and amalgamation of one DIT and one MIT produces T3. TPO catalyzes this reaction.

J. Exp. Clin. Med., 2012; 29: S277-S279 


\section{Giriş}

\section{Iyot metabolizması}

İyot, Fransız kimyacı Bernard Courtois tarafindan 1811'de bulunan periyodik tabloda halojenler grubuna dahil olan bir elementtir. İsmini, iyodun gaz halindeki rengi olan menekşe-mor manasına gelen Yunanca "iodes"den almıştır (Swain, 2005; Newsome ve Hickmen, 2010).

\section{İyot kaynakları}

Vücudumuzda bulunan iyodun major kaynağı diyettir. İyodun gıdasal kaynakları arasında iyotlu tuz, deniz ürünleri, süt ürünleri, tahıllar, patates ve bazı ilaçlar (amiodaron ve mineral tabletleri) bulunmaktadır (Pennington ve Young, 1991). Normal tiroit fonksiyonlarının karşılanması için tavsiye edilen günlük iyot alımı; bebeklerde $90 \mu \mathrm{g} / \mathrm{gün}, 6$-12 yaş çocuklarda $120 \mu \mathrm{g} / \mathrm{gün}$, yetişkinlerde $150 \mu \mathrm{g} /$ gün, gebelik ve süt verme durumunda ise $250 \mu \mathrm{g} /$ gündür. Gelişmiş ülkelerde sofra tuzuna iyot eklenmesi ile günlük alınan miktar 500 $\mu \mathrm{g}$ 'a kadar çıkmıştır. Diyetle alınan iyot miktarı son derece önemlidir. Az miktardaki bir iyot eksikliği bile tiroit bezinin büyümesine neden olur (Barrett ve ark., 2010; Newsome ve Hickmen, 2010). Diyetle alınan iyodun dışında, tiroit bezi ya da periferal dokularda tiroit hormonlarının deiyodinasyonu ile açığa çıkan iyot diğer önemli kaynağı oluşturmaktadır (Ishii ve ark., 1983; LoPresti ve ark., 1989).

\section{İyodun vücutta dağılımı}

Diyetle alınan iyot moleküler $\left(\mathrm{I}_{2}\right)$ formda ise kolaylaşt1rılmış difüzyonla emilirken, iyodür formunda ise $\left(\mathrm{I}^{-}\right)$emilimi gastrik mukozada bulunan sodyum-iyodür simporter taşı1cı proteini yardımı ile gerçekleşir. Bu taşıyıcı protein; tiroit, meme dokusu, tükrük bezleri ve serviks gibi iyodu kullanan ve konsantre eden dokularda bulunur (Spitzweg ve ark., 2001).

T3 ve T4 gibi iyotlu aminoasitler yapıları bozulmadan barsak duvarını geçerler. Kısa zincirli iyodopeptidler de peptid bağı kırılmadan emilebilir (Wynn, 1961). Plazma inorganik iyot miktarı 0,8-6 $\mu \mathrm{g} / \mathrm{L}$ 'dir. İdrardaki iyot miktarı da plazma ile uyumludur (5-10 yaş: $32,5 \mu \mathrm{g} / \mathrm{g}$ kreatinin, genç: 50 $\mu \mathrm{g} / \mathrm{g}$ kreatinin ve yetişkinde: $75 \mu \mathrm{g} / \mathrm{g}$ kreatinin) (Newsome ve Hickmen, 2010).

\section{Tiroit bezi dışındaki dokular tarafından iyodun alın-} ması

İyodun renal klirensi 30-50 mL plazma/dk'dır. İnsanlarda, tubuler sekresyonu veya aktif transportuna dair bilgi olmadığından, renal klirensi öncelikle glomerüler filtrasyona bağlıdır (Perry ve Hughes, 1952). Fetüse yeterli iyodun sağlanması için plasenta tarafından ve yenidoğanın ihtiyacının karşılanması için de meme bezi tarafından absorbe edilir (Newsome ve Hickmen, 2010). Özellikle iyot alımından sonraki ilk 24 saatte anne sütü fazla miktarda iyodür içerir ve bu içerik alınan iyot miktarıyla direkt ilişkilidir (Weaver ve ark., 1960).

\section{İyot' un tiroit bezi tarafindan alınması, tiroit hormon sentez ve salgilanması \\ 6-12 mg'a kadar olabilen total vücut iyodunun \% 90 ka- darını tiroit içindeki iyot oluşturur (Newsome ve Hickmen, 2010). İnorganik iyot, folikül hücrelerinin kapillere yakın bazolateral membranında yerleşmiş olan ve elektrokimyasal}

gradyente karşı iki $\mathrm{Na}^{+}$iyonu ve bir I- iyonunun hücre içine geçişini sağlayan sodyum-iyodür simporteri (Natrium-iodide symporter, NIS) ile hücre içine alınır (Chambard ve ark., 1983). Bu pompa sayesinde plazmaya göre 20-40 kat büyük hücre içi I- konsantrasyonu gerçekleşir (Barrett ve ark., 2010). $\mathrm{Bu}$ pompanın aktivitesi TSH ile arttırılır ve bu pompa tiroit hormonlarının sentezinde hız sınırlayıcı basamaktır (Whitley, 2001). Tükrük bezi, mide mukozası, plasenta, koroid pleksus, meme bezleri ve bu dokulardan köken alan bazı tümörler de NIS eksprese eder ve konsantrasyon gradyentine karşı iyodür taşıyabilirler ama bu dokulardaki taşıyıcılar TSH tarafından etkilenmez (Barrett ve ark., 2010). Plazma iyodür miktarı ile pompa aktivitesi arasında ters bir ilişki vardır. Plazma iyodür miktarı arttığında pompa aktivitesinde azalma görülürken, plazma miktarı azaldığında ise pompa aktivitesinde artma görülmektedir. Yüz elli $\mu \mathrm{g} /$ gün iyotlu diyette, tiroit bezi, dakikada 10-25 ml serumu iyodürden temizler. Bu şekilde plazmaki iyodür miktarı saatte \% 12 kadar azalır. İyot eksikliğinde bu h1z 100 ml/dk'ya kadar artabilir veya 500-600 $\mu \mathrm{g} /$ gün kronik iyot alımı ile 3-4 ml/dk kadar olabilir (DeGroot, 1966). Normal sentez ve salgılama hızında tiroide $120 \mu \mathrm{g} /$ gün iyodür girer. Tiroit bezi T3 ve T4 formunda $80 \mu \mathrm{g} /$ gün iyodür salgılarken $40 \mu \mathrm{g} /$ gün iyodür de hücre dışı sıvıya geri geçer. T3 ve T4 karaciğer ve diğer dokularda metabolize olur ve bu dokulardan da hücre dışı sıvıya her gün $60 \mu \mathrm{g}$ iyodür geçer. Bazı tiroit hormon metabolitleri safraya atılır ve bir kısmı enterohepatik dolaşımda geri emilir ama gayta ile yaklaşık 20 $\mu \mathrm{g} /$ gün net iyodür atılımı olur. Hücre dışı sıvıya giren toplam iyodürün (600 $\mu \mathrm{g} / \mathrm{gün}), \%$ 2' si tiroide girer ve \% 80’i idrarla atılır (Barrett ve ark., 2010).

Tiroit hücreleri foliküllerde organize haldedir. Folikül, kolloid olarak isimlendirilen vizköz bir çekirdeği saran tiroit hücre kümesidir. Kolloidin ana bileşeni foliküler hücrelerde fazlaca üretilen 660.000 dalton ağırlığında bir glikoprotein olan tiroglobulindir (Grotzke, 2010). Tiroglobulin tiroit bezinde en bol bulunan proteindir ve konsantrasyonu folikül lümeninde 200-300 g/L'ye ulaşabilir. Asıl fonksiyonu tiroit hormonları sentez ve depolanması için polipeptid iskeleti sağlamaktır.

Foliküler lümenin iyodür stoğu için iki adımlı transport sistemi gereklidir. Birincisi plazmadan folikül hücrelerine iyodür geçmesini sağlayan NIS transport sistemidir. İyodürün folikül lümenine geçmesi için gerekli ikinci transport sistemi; tiroit hücresi apikal membranını geçerek kolloide girmesini sağlayan pasif transporttur. Bunu sağlayan protein veya proteinler henüz bilinmemektedir. $\mathrm{Bu}$ taşınma işleminin en azından bir kısmının Pendrin olarak isimlendirilen bir " $\mathrm{Cl}^{-} / \mathrm{I}^{-1}$ değiştirici bir protein aracılığı ile olduğu düşünülmektedir (Barrett ve ark., 2010). Tiroide giren iyodür tirozil kalıntılar1na bağlanmadan önce kısa bir süre serbest olarak kalır. Radyoaktif iyot uygulamasından sonra tiroit içi iyodürün anlamlı bir kısmının 10-20 dakika serbest halde kaldığı gösterilmiştir (Ingbar, 1955).

Tiroit hormon sentezinin ilk adımı tiroglobulindeki tirozil kalıntılarına iyodürün eklenmesidir. Bu eklenme, apikal plazma membranı-folikül lümeni sınırında, $\mathrm{H}_{2} \mathrm{O}_{2}$, tiroperoksidaz (TPO), iyodür ve tiroglobulin varlığında oluşur. İlk olarak iyodür okside olur ve daha sonra tiroglobulinin tirozil kalıntısı ile birleşir. En fazla iyodinasyon tiroglobulin vezikül içinde iken gerçekleşir. Tiroglobulindeki tüm tirozil kalıntıları iyodinasyona açık değildir. 


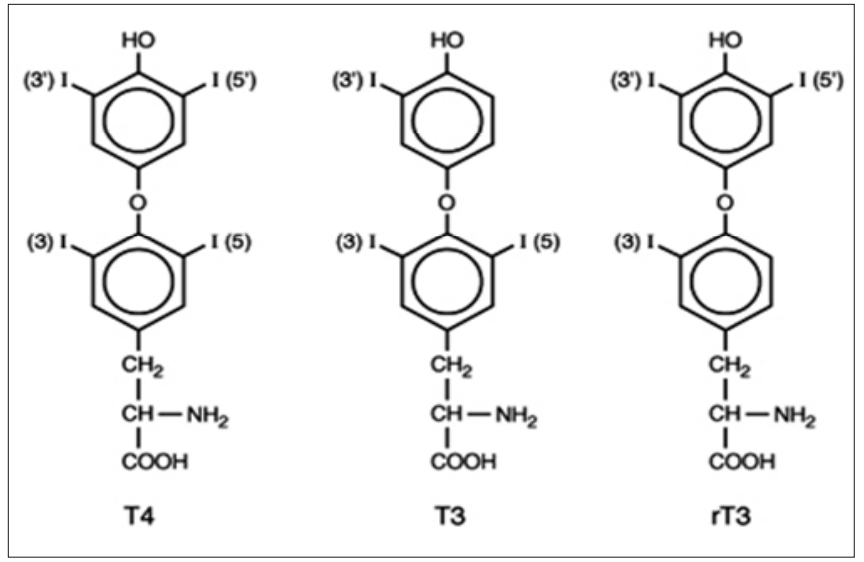

Şek. 1. Tiroit hormonları. T3 (Triiyodotironin), rT3 (reverse triiyodotironin), T4 (Tiroksin).

Moleküldeki 123 tirozil kalıntısının az bir kısmı (yaklaşık $\%$ 10) iyodinize olur (Newsome ve Hickmen, 2010). Hormon sentezinde sonraki adım komşu iki monoiyodotirozil (MIT) kalıntısının diiyodotironin (DIT) oluşturmak üzere birleşmesidir. İki DIT birleşerek T4'ü, bir DIT ve bir MIT birleşerek T3'ü oluşturur (Şek. 1). Bu reaksiyonu TPO katalizler. Bu birleşme ayrı tiroglobulin zincirleri arasında veya aynı proteinin katlanması ile oluşur (Berndorfer ve ark., 1996).Normal insan tiroidinde, iyodinize bileşikler \% 23 MIT, \% 33 DIT, \% 35 T4 ve \% 7 T3 şeklinde dağılır (Barrett ve ark., 2010).

Hipofiz bezinden salınan TSH, folikül hücresi bazal membranında bulunan TSH reseptörlerine bağlanır ve cAMP bağımlı bir mekanizma ile kolloidde depolanan tiroglobulinin lizozomlara alınarak hidroliz edilmesini ve T4, T3, MIT ve
DIT'1n serbestleşmesini sağlar. Hücre içine alınan MIT ve DIT hemen deiyodinize edilir ve elde edilen iyot sonraki hormon sentezinde tekrar kullanılır. T4 ve T3, tiroit içi deiyodinasyona dirençlidir ve dolaşıma salgılanır (Newsome ve Hickmen, 2010). Tiroit günde $80 \mu \mathrm{g} \mathrm{T} 4,4 \mu \mathrm{g}$ T3 ve $2 \mu \mathrm{g}$ reverse T3 (rT3) salgılar (Barrett ve ark., 2010). Tüm T4 üretimi tiroit içinde olmasına karşı, T3'ün yaklaşık \% 80'i T4'ün tiroit dışı deiyodinasyonu ile gerçekleşir. T4'den T3 üretimi için asıl organlar karaciğer ve böbrek olsa da, birçok dokunun da T3 üretim kapasitesi vardır (Newsome ve Hickmen, 2010).

Tiroit bezinde başka iyodinize bileşikler de bulunur. Bunlardan biri olan tiroalbumin Hashimoto tiroiditi, tiroit karsinomu ve tirotoksikoz gibi tiroit hastalıklarında artar (Wolff, 1964; Dai ve ark., 1996). Ayrıca, tiroit bezi bazı lipidleri de iyodinize edebilir. Lipidlerin iyodinasyonunun $\mathrm{H}_{2} \mathrm{O}_{2}$ üretimini ve dolayısıyla tiroglobulin iyodinasyonunu inhibe ettiği öne sürülmektedir (Johanson ve ark., 1988). Az miktarda T3, T4 ve rT3, karaciğerde glukuronid veya sülfatla konjuge edilerek safra ile atılsa veya asetik asit analoglarına metabolize edilse de, tiroit hormonları çoğunlukla deiyodinasyonla metabolize olur. D1, D2 ve D3 olarak isimlendirilen üç deiyodinaz vardır. D1, karaciğer ve böbrekte yüksek miktarda bulunur ve T4'ü, eşit miktarlarda T3 ve rT3'e dönüştürür. $\mathrm{Bu}$ enzim hipertiroidi hastalarında T3'ün ana kaynağıdır ve propiltiyourasil (PTU) ile inhibe edilir. D2, kas, beyin, deri, hipofiz, kahverengi yağ dokusu ve plasentada fazla miktarda bulunur ve T3 oluşumuna katk1 sağlar. D3 beyin ve plasentada bulunur ve sadece 5. pozisyona etki ile T4'ü, rT3'e ve T3'ü 3,3'diiyodotironine dönüştürür. D3 dolaşımdaki rT3'ün ana kaynağıdır (Barrett ve ark., 2010; Newsome ve Hickmen, 2010).

\section{KAYNAKLAR}

Barrett, K.E., Barman, S.M., Boitano, S., Brooks, H.L., 2010. Ganong's Review of Medical Physiology. The McGraw-Hill Education (Asia), Singapore. pp. 301-314.

Berndorfer, U., Wilms, H., Herzog, V., 1996. Multimerization of thyroglobulin (TG) during extracellular storage: Isolation of highly cross-linked TG from human thyroids. J. Clin. Endocr. Metab. 81, 1918-1926.

Chambard, M., Verrier, B., Gabrion, J., Mauchamp, J., 1983. Polarization of thyroid cells in culture: Evidence for the basolateral localization of the iodide "pump" and of the thyroid-stimulating hormone receptor-adenyl cyclase complex. J. Cell Biol. 96, 1172-1177.

Dai, G., Levy, O., Carrasco, N., 1996. Cloning and characterization of the thyroid iodide transporter. Nature. 379, 458-460.

DeGroot, L.J., 1966. Kinetic analysis of iodine metabolism. J. Clin. Endocr. Metab. 26, 149.

Grotzke, M., 2010. Chapter 22: The Thyroid Gland. Clinical Chemistry. Bishop, M.L., Fody, E.P., Schoeff, L.E. Sixth eds. Lippincott Williams\&Wilkins, pp: 490-495.

Ingbar, S.H., 1955. Simultaneous measurement of the iodide-concentrating and protein-binding capacities of the normal and hyperfunctioning human thyroid gland. J. Clin. Endocr. Metab. 15, 238.

Ishii, H., Inada, M., Tanaka, K., Mashio, Y., Naito, K., Nishikawa, M., Matsuzuka, F., Kuma, K., Imura, H., 1983. Induction of outer and inner ring monodeiodinases in human thyroid gland by thyrotropin. J. Clin. Endocr. Metab. 57, 500-505.

Johanson, V., Ofverholm, T., Ericson, L.E., 1988. Forskolin-induced elevation of cyclic AMP does not cause exocytosis and endocytosis in rat thyroid follicle cells in vivo. Mol. Cell Endocrinol. 59, 27-34.

LoPresti, J.S., Fried, J.C., Spencer, C.A., Nicoloff, J.T., 1989. Unique alterations of thyroid hormone indices in the acquired immunodeficiency syndrome (AIDS). Ann. Intern. Med. 110, 970-975.

Newsome, S., Hickmen, P.E., 2010. Chapter 49: Thyroid. Clinical Chemistry. Kaplan, A.L., Pesce, J.A. Fifth eds. Elsevier, pp: $948-960$.

Pennington, J.A.T., Young, B.E., 1991. Total diet study nutritional elements, 1982-1989. J. Am. Diet. Assoc. 91, 179-83.

Perry, W.F., Hughes, J.F.S., 1952. The urinary excretion and thyroid uptake of iodine in renal disease. J. Clin. Invest. $31,457$.

Spitzweg, C., Harrington, K.J., Pinke, L.A., Vile, R.G., Morris, J.C., 2001. Clinical review 132: The sodium iodide symporter and its potential role in cancer therapy. J. Clin. Endocr. Metab. 86, 3327-3335.

Swain, P.A., 2005. Bernard Courtois (1777-1838) famed for discovering iodine (1811), and his life in Paris from 1798. Bull. Hist. Chem. 30, 103-111.

Weaver, J.C., Kamm, M.L., Dobson, R.L., 1960. Excretion of radioiodine in human milk. JAMA. 173, 872.

Whitley, R.J., 2001. Chapter 40: Thyroid function. Tietz Fundamentals of Clinical Chemistry fifth edition. Carl A. Burtis, Edward R. Ashwood. W.B. Saunders Company, Philadelphia. 839-856.

Wolff, J., 1964. Transport of iodide and other anions in the thyroid gland. Physiol. Rev. 44, 45-90.

Wynn, J.O., 1961. Components of the serum protein-bound iodine following administration of I131-labeled hog thyroglobulin. J. Clin. Endocr. Metab. 21, 1572-1961. 